\title{
RESILIENCE ASSESSMENT FOR THE BUILT ENVIRONMENT OF A VIRTUAL CITY
}

\author{
Sebastiano Marasco ${ }^{1}$, Ali Zamani Noori ${ }^{1}$, and Gian Paolo Cimellaro ${ }^{2}$ \\ ${ }^{1} \mathrm{PhD}$ Student, Department of Civil Structural \& Geotechnical Engineering \\ Politecnico di Torino, Italy \\ \{sebastiano.marasco@polito.it, ali.zamani@polito.it\} \\ ${ }^{2}$ Visiting Professor, Department of Civil and Environmental Engineering \\ University of California, Berkeley, CA, USA \\ gianpaolo.cimellaro@polito.it
}

Keywords: Resilience, Virtual city, Nonlinear, Simulation

\begin{abstract}
This paper presents a new methodology to predict the potential damage and physical impacts of earthquake on the built environment through nonlinear dynamic simulations. A virtual city consisting of different building categories has been designed. Four building sectors that provide essential functions to a community, including housing (residential building, hotel, shelter, etc.), education (school, university, library, etc.), business (shopping center, retail store, heavy industry, etc.), and public services (hospital, police station, church, airport, etc.) are considered. Once the buildings are integrated into the city, parallel simulations are applied to compute the system functionality following a disruptive scenario. Nonlinear response of a multi degree of freedom model for each residential building is obtained considering the dominant modal shapes and irregularities. The post-elastic behavior is estimated through collapse analysis which allows identification of the over strength factor associated to the most probable failure mechanism of the building. Monte Carlo Simulations (MCS) are applied in order to take into account the epistemic uncertainties associated with geometry and mechanical properties within the range of observations. For each set of buildings' data, the nonlinear dynamic analysis is performed through SAP2000 application programming interface (API) in order to assess the dynamic response of the buildings in an organized and automatic fashion. Accordingly, the city is mapped into different zones representative to the possibility of having different levels of damage (complete, extensive, moderate, and slight). This methodology allows decision-makers to explore how their community will respond to a disruptive event, quantify the performance of critical infrastructure following a hazard, and to plan better resilience-building strategies in order to minimize losses and recovery time.
\end{abstract}




\section{INTRODUCTION}

According to the World Bank, disasters have killed 58,000 people on average each year and affected another 225 million people worldwide since 1990. The rising of global populations and the massive economic development in areas prone to disasters have increased the chance of catastrophic incidents, which leads to disruption of buildings and infrastructure. Over the years, community resilience has attracted tremendous attention due to the increasing number of natural and man-made disasters. The concept of resilience is multi-dimensional, and therefore involves various subjects of different disciplines. In engineering, resilience is the ability to "withstand stress, survive, adapt, and bounce back from a crisis or disaster and rapidly move on". It can also be defined as "the ability of social units (e.g. organizations, communities) to mitigate hazards, contain the effects of disasters when they occur, and carry out recovery activities in ways to minimize social disruption and mitigate the effectors of further earthquakes". The absence of a concise and methodical approach makes it extremely difficult to evaluate resilience. This paper focuses on the resilience-based design and assessment of the residential buildings in a virtual city. The objective is to predict, with the set of physical simulation models, the potential damage and physical impacts of an earthquake and other hazards (natural disasters and man-made attacks) on the built environment. A virtual city consisting of different buildings categories and infrastructure was designed. Four building sectors that provide essential functions to a community including housing (residential building, hotel, shelter), education (school, university, library), business (shopping centers, retail stores, heavy industries), and public services (hospital, police station, churches, airport etc.) are considered. Five critical infrastructure systems supporting a community's indispensable demands, i.e., water and waste water distribution system, gas networks, power grids, transportation and communication networks were also designed. Once the infrastructure was integrated into the city, parallel simulations were applied in order to compute their functionality when exposed to a disruptive scenario.

Given the large number of buildings in a city, the seismic simulation of the buildings cannot be easily implemented without huge computational effort. Thus, several numerical models have been proposed to simulate the seismic damage to buildings in the recent years. Basically, the simulation models are classified into a data-driven method and a physics-driven method. The first is based on statistical data obtained from previous earthquakes. The main limitation is due to the inadequacy and leakage of statistical data for any world areas. To overcome these intrinsic limitations, the physics-driven methods have been progressing in recent years. The building seismic damage is based on the structural analysis of an individual building subjected to a given seismic input.

Given limited attribute data of each building and the large number of buildings in an urban area, the seismic response prediction model of buildings must be relatively simple to reduce the computational time requested by the analyses.

In this paper, a simplified and efficient physical approach is presented. Nonlinear response of a Multi Degree Of Freedom (MDOF) model of each building is obtained considering the dominant modal shapes and irregularities. A trilinear backbone curve is used to simulate the building's seismic response. The elastic trend of this curve is assessed through a multi-modal approach. A nonlinear static procedure is carried out to evaluate the yield shear force, which is identified as the horizontal force causing the first plastic hinge in the weakest base column.

A collapse analysis is carried out for each building to assess the post-elastic building's behaviour. Considering a global collapse mechanism, the over strength factor is identified according to the geometry of the structural elements composing the building. 
Furthermore, the epistemic uncertainties associated with geometry and mechanical properties within the range of observations are taken into account by performing MCS. At each step of MCS a set of parameters are assigned to each building and the associated backbone curve is obtained through an algorithm developed in MATLAB (MATLAB, 2012) by using parallel computing features. The SAP2000 (Computers \& Structures, Inc.) application programming interface (API) is used to import, change the building's parameters at each step of the simulation, and perform nonlinear dynamic analysis with a given seismic input.

The SAP2000 advanced numerical modules permit efficient pre- and post-analysis computations. In fact, the automated post-processing analysis allows us to extract all the response parameters needed to estimate the level of damage for each building. The Figure 1 depicts the typical data flow using the SAP2000 API.

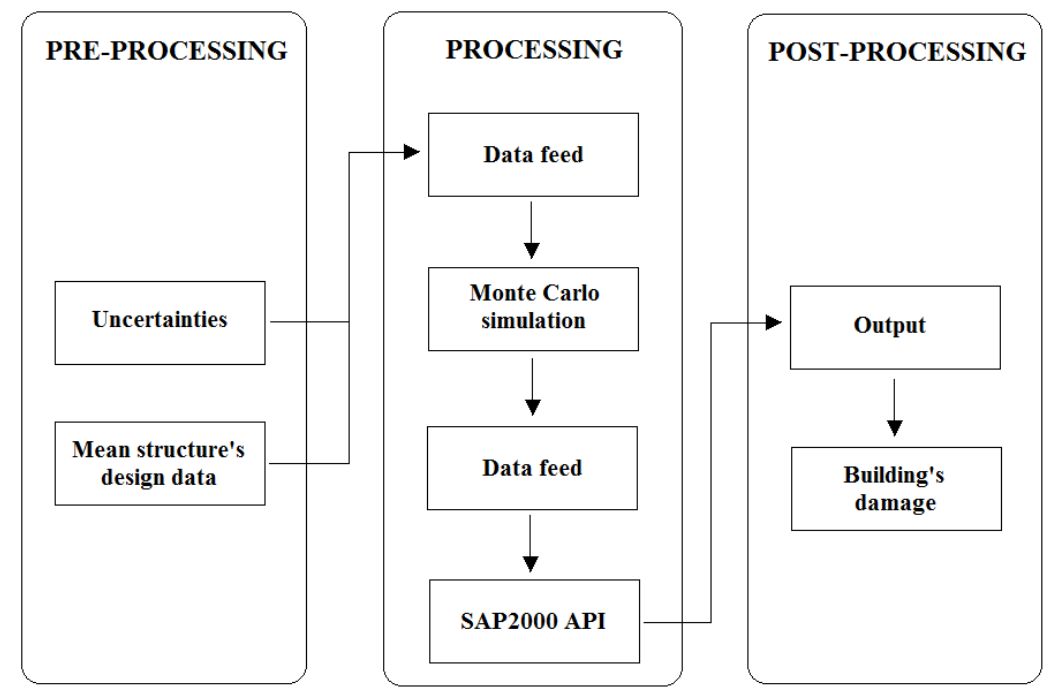

Figure 1. Data flow.

\section{BUILDINGS DATABASE}

The virtual city has been designed based on the buildings stock for the city of Turin, Italy. Four building sectors that provide essential functions to a community, including housing (residential building, hotel, shelter, etc.), education (school, university, library, etc.), business (shopping center, retail store, heavy industry, etc.), and public services (hospital, police station, church, airport, etc.) are considered.

The plan dimensions of each building have been gathered through CADMAPPER file for the entire city of Turin. In addition, the number of floors have been obtained by the shape-file of "Carta Tecnica Comunale (CTC)" of the city of Turin, available at the website http://www.comune.torino.it/geoportale/.

The building inventory of the city is based on the building typology concept already used in many European countries at national and regional levels. However, the lack of information about some buildings makes it difficult to have perfect knowledge of any individual building. For this reason, some building's attributes (e.g. year of construction, type of deck) have been assigned based on historical data. Six different categories of construction year have been utilized according to standard Italian codes. 


\begin{tabular}{llllll}
\hline I & II & III & IV & V & VI \\
\hline$<1916$ & $1916-1937$ & $1938-1974$ & $1975-1996$ & $1996-2008$ & $>2008$ \\
\hline
\end{tabular}

Table 1. Categories of year of construction.

The numbers of buildings for each year of construction category have been assigned according to Cities on Power (CoP) European program research for the city of Turin (Fracastoro et al., 2013).

Corrado et al. (2012) provided typical Italian building construction elements depending on the year of construction. Classification of building construction elements (e.g. deck, wall, etc.) plays a key role in the assessment of mass. Seven different typical deck and three typical external walls have been selected and distributed based on their year of construction (Figure 2).

\begin{tabular}{|c|c|c|}
\hline \multicolumn{2}{|c|}{ DESCRIPTION } & YEAR \\
\hline उग5. & Vault ceiling with solid bricks & $<1900$ \\
\hline 它岳岳 & $\begin{array}{c}\text { Ceiling with wood beams and } \\
\text { hollow bricks }\end{array}$ & $<1900$ \\
\hline$\square$ & Ceiling with reinforced concrete & $1900-1930$ \\
\hline Inimimiminger & $\begin{array}{c}\text { Vault ceiling with bricks and steel } \\
\text { beams }\end{array}$ & $<1930$ \\
\hline Irasens & $\begin{array}{l}\text { Vault ceiling with hollow bricks and } \\
\text { steel beams }\end{array}$ & $1910-1940$ \\
\hline 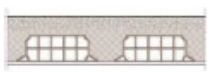 & $\begin{array}{l}\text { Ceiling with reinforced brick- } \\
\text { concrete slab }\end{array}$ & $>1930$ \\
\hline 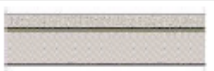 & $\begin{array}{l}\text { Ceiling with reinforced brick- } \\
\text { concrete slab, low insulation }\end{array}$ & $>1976$ \\
\hline
\end{tabular}

(a)

\begin{tabular}{|c|c|c|}
\hline \multicolumn{2}{|c|}{ DESCRIPTION } & YEAR \\
\hline $\bar{\square}$ & Solid brick masonry $(25 \mathrm{~cm})$ & $1900-1950$ \\
\hline 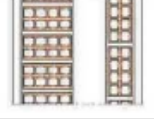 & Hollow wall brick masonry $(30 \mathrm{~cm})$ & $>1930$ \\
\hline 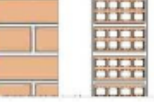 & $\begin{array}{l}\text { Hollow wall brick masonry with } \\
\text { solid and hollow bricks }(40 \mathrm{~cm})\end{array}$ & $1930-1975$ \\
\hline
\end{tabular}

(b)

Figure 2. Typical Italian building's decks (a) and walls (b) used for residential occupancy in different years (Corrado et al., 2012). 
All the buildings have been divided into groups based on material: concrete, masonry, and steel. Considering limited information in the building attribute data, an accurate determination of the nonlinear structural parameters is rather challenging. The major objectives of this work are to provide a simplified and accurate method for assessing the dynamic response of residential buildings in a generic built environment. For this purpose, the geometric characteristics of the structural elements (e.g. columns and beam sizes) have been defined in order to respect all the technical standards for a given year of construction and for a given seismic hazard scenario (medium or high level).

\section{NONLINEAR MODEL}

A large component to an urban environment is residential buildings. When a catastrophic event such as an earthquake occurs in a built environment, the consequential structural damage may cause high losses (casualties, repair costs, and repair time). Thus, a concise and methodical approach is needed to estimate the fragility of the building framework. Nonlinear MDOF shear model is able to satisfactorily capture the nonlinear properties of multi-story buildings, predict the Engineering Demand Parameters (EDPs), and assess a reasonable level of damage (Lu et al. 2014; Xu et al. 2014). In the proposed approach, the inter-story behavior of a regular building is simulated through a trilinear backbone curve (Figure 3). Many studies claim that the trilinear backbone curve model can accurately represent the building's response in terms of inter-story (Vamvatsikos and Cornell 2005; Shi 2014).

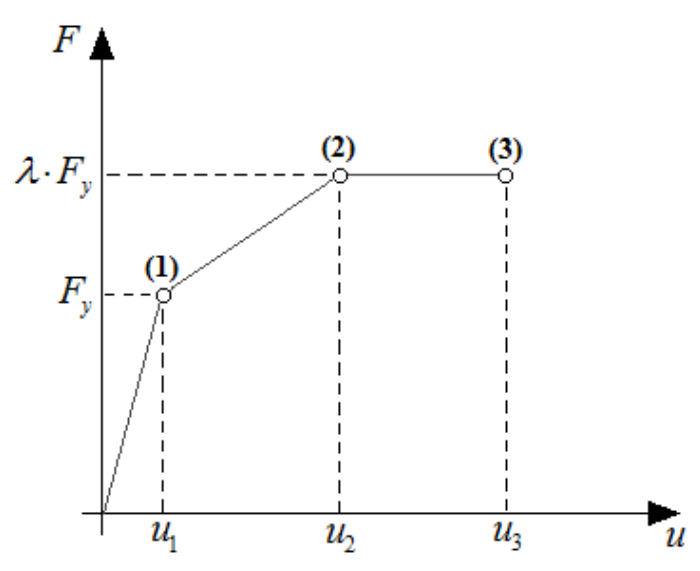

Figure 3. Trilinear backbone curve.

The first point of the trilinear backbone curve (1) indicates the yield point $\left(\lambda \cdot F_{y}-u_{1}\right)$ corresponding to the formation of the first plastic hinge in the weakest base column. After the yield point, the stiffness is significantly reduced until the next point (2), for which the maximum shear base capacity $\left(\lambda \cdot F_{y}\right)$ is reached. The ultimate point (3) corresponds to the collapse of the building (complete damage). The evaluation of the shear base and top displacement parameters for each point is discussed in the following subsections.

The three main points of the curve are evaluated using a nonlinear static approach for a MDOF system. To achieve this goal, a MATLAB algorithm has been developed considering the uncertainties on the geometric and mechanical parameters used in the analyses. Variation of the parameters within an acceptable range is considered through an MCS obtaining a set of trilinear backbone curves for each building. The ranges of the main building's parameters are 
selected according to the knowledge level of the building. In addition, the deterioration of the mechanical properties (such as strength and elastic modulus of concrete) is taken into account through the aging equation proposed by Eurocode 2 (EC2, 2004) according to the year of construction. Once the Matlab algorithm evaluates the trilinear backbone curve at each step of MCS, the SAP2000 API is used to apply to all the buildings the data set obtained by the algorithm. This automated procedure is capable of reducing the computational time and analyze the dynamic responses dispersion caused by the data uncertainty. Therefore, the mean response and associated dispersion for each building within the virtual city can be estimated. This approach is suitable to allow a decision-maker the ability to explore how their community responds to a disruptive event and quantify the mean performance of buildings and their uncertainty in the dynamic response after a hazard.

Assimilating the dynamic nonlinear response of a structural system to a unique backbone curve leads to analyze the building as a nonlinear equivalent Single Degree Of Freedom (SDOF) model. Considering an SDOF system allows for a reduction in the computational effort needed to assess the response of a large number of structures. Finally, due to limited amount of detailed building information about its dynamic behavior, the hysteresis is considered according to the Takeda model (Takeda et al., 1970) implemented in SAP2000.

\subsection{Elastic parameters}

Generally, the geometry of a residential building is mostly regular in plan and elevation, therefore the mass and stiffness can be assumed to be mostly uniformly distributed. In these cases, the evaluation of the response of MDOF system with a nonlinear static procedure is close to the real response of the structure.

Thus, a nonlinear static analysis is performed to assess the base shear and top displacement values corresponding to the formation of the first plastic hinge at the base level (yield point). In order to consider all Degrees Of Freedom (DOFs), the stiffness matrix of the structure is evaluated considering the building as a bending type system. Since the load patterns are applied on two main directions of the buildings, the modal characteristics are derived by considering the stiffness matrix in the two directions for a 2D system. Thereafter, the static condensation procedures are performed to reduce the number of DOFs to the translational DOFs. Moreover, the model assumes that the mass of each story is concentrated in the center of the mass on its elevation and represented by a mass point (Figure 4). 


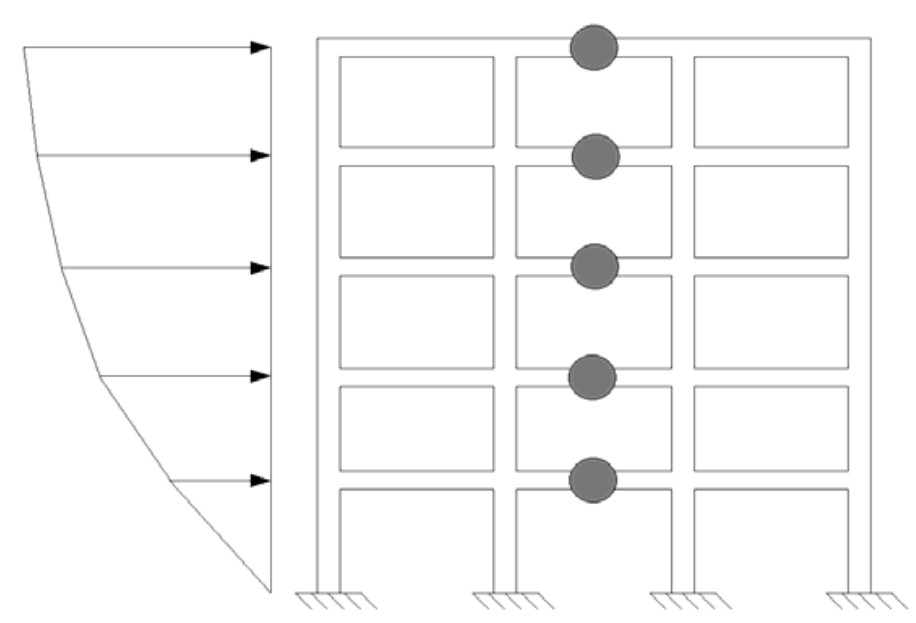

Figure 4. Concept of nonlinear MDOF system.

Equations (1) and (2) summarizes the global stiffness and mass matrices of a MDOF model, respectively.

$$
\begin{gathered}
K=\left[\begin{array}{cccc}
k_{11} & k_{12} & \cdots & k_{1 d o f} \\
k_{21} & k_{22} & \cdots & k_{2 d o f} \\
\vdots & \vdots & \vdots & \vdots \\
k_{d o f 1} & k_{\text {dof } 2} & \cdots & k_{\text {dofdof }}
\end{array}\right] \\
M=\left[\begin{array}{cccc}
m_{1} & 0 & \cdots & 0 \\
0 & m_{2} & \cdots & 0 \\
\vdots & \vdots & \vdots & \vdots \\
0 & 0 & \cdots & m_{d o f}
\end{array}\right]
\end{gathered}
$$

where $d o f$ represents the total number of DOFs.

The yielding base shear force is assessed by applying a monotonic load pattern on the building proportional to a given modal shape. A multi-modal approach is carried out to consider all the modal shape contributions, especially for buildings that have geometric irregularities (Equation (3)).

$$
\Phi_{t o t}=\sum_{i=1}^{d o f}\left\{\Phi_{i}\right\} \cdot g_{i}
$$

where $\Phi_{t o t}$ is the modal shape considering all modal contributions $\left(\Phi_{i}\right)$. The modal participation factors are represented by the term $g_{i}$.

\subsection{Post-elastic parameters}

Once the structure reaches the yield point, the stiffness is significantly reduced until point (2) for which the maximum shear base capacity is reached. Thus the top shear base remains constant and the top displacement increases (perfectly plastic behavior) until the ultimate value. The maximum shear base capacity is estimated through the kinematic approach of the lim- 
it analysis (Greenberg-Prager theorem). The general global collapse mechanism of a frame subjected to a distribution of horizontal forces (proportional to a given modal shape) is considered (Figure 5).

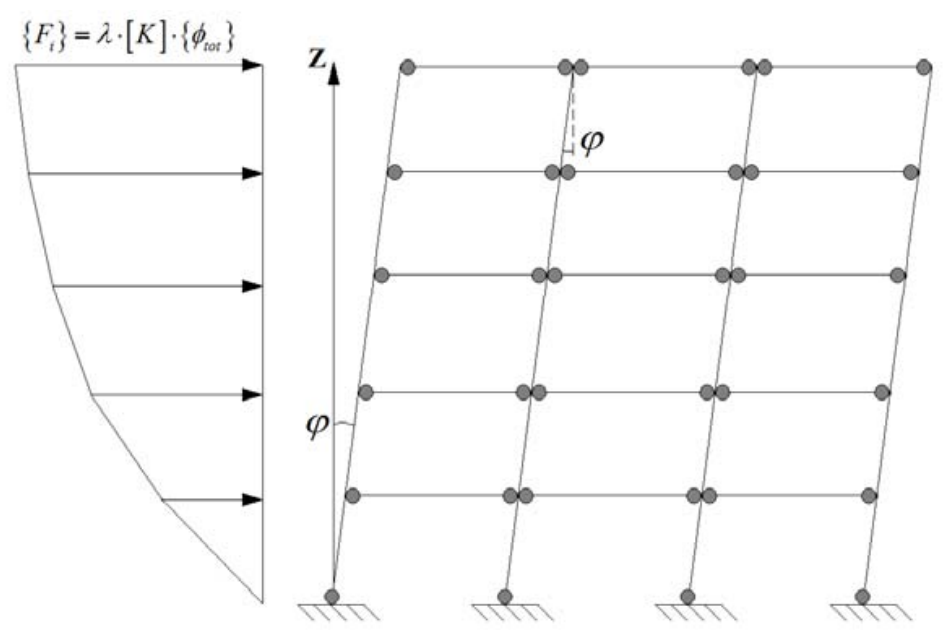

Figure 5. Global collapse mechanism.

This approach leads to take into account the strength contribution of all the structural elements (beams and columns). According to the kinematic theorem of the limit analysis, the global over-strength factor $(\lambda)$ is assessed by the ratio between the internal and external work of the structural system with equal columns and beams dimensions (Equation (4)).

$$
\lambda=\frac{n_{c} \cdot M_{y, c}+2 \cdot n_{\text {span }} \cdot \operatorname{dof} \cdot M_{y, b}}{\sum_{i=1}^{d o f}\left\{F_{i}\right\} \cdot\left\{z_{i}\right\}}
$$

where $M_{y, c}$ and $M_{y, b}$ are the yielding bending moment for the columns and beams, respectively. The parameters $n_{c}$ represents the number of columns, $n_{\text {span }}$ indicates the number of spans in the considered direction, and dof is the number of master DOFs which corresponds to the story number of the building. The external work is given by the denominator expression and it is due to the horizontal load patterns $\left\{F_{i}\right\}$ multiplied by the distance between the considered story and the base at each elevation level $\left\{z_{i}\right\}$.

One of the limitations of this procedure consists of the load pattern's shape. In fact, the monotonic horizontal force distribution does not change its shape due to the progressive formation of the plastic hinges in the columns (non-adaptive approach). In addition, a global mechanism has been considered as representative of the collapse mechanism. This hypothesis is reasonable for regular buildings designed according to the seismic standard codes. When a building is not well designed or seismically retrofitted (such as an old building), the collapse can be caused by a local mechanism for which the over-strength factor assumes lower values. In these cases, the possible local mechanisms have to be identified and the over-strength factor will be assumed as the minimum values among all the defined factors.

Once the shear base capacity is determined, the top displacements corresponding to points (2) and (3) of the trilinear backbone curve ( $u_{2}$ and $u_{3}$ in Figure 3$)$ have to be assessed. Since the shear base capacity is previously evaluated, the definition of reduction factor $\left(R_{\mu}\right)$ can be 
used to calculate the displacement $u 2$. The reduction factor accounts for ductility, overstrength, redundancy, and damping of a structural system (Equation (5)).

$$
R_{\mu}(T, \mu, \xi)=\frac{F_{E L}(T, \xi)}{\lambda \cdot F_{y}(T, \mu, \xi)}
$$

where $\lambda \cdot F_{y}$ is the maximum shear capacity and $F_{E L}$ represents the equivalent elastic shear force. As mentioned previously, the reduction factors depend on ductility $(\mu)$, over-strength $(\lambda)$, damping $(\xi)$ and elastic building characteristics (such as period, $T$ ). Several mathematical formulations have been proposed for evaluating the reduction factor. One of the most used expressions is based on the equal energy rule (short period systems, $T<0.5 \mathrm{~s}$ ) or equal displacement rule (long period systems, $T>0.5 \mathrm{~s}$ ) (Equation (6)).

$$
\left\{\begin{array}{l}
R_{\mu}=\sqrt{2 \cdot \mu-1} \quad(T<0.5 s) \\
R_{\mu}=\mu(T>0.5 s)
\end{array}\right.
$$

The ductility parameters are expressed as a ratio between the ultimate displacement and the displacement for which the maximum shear capacity occurs. According to the proposed trilinear backbone curve, the ductility is given by the ratio between displacements $u_{2}$ and $u_{3}$.

Furthermore, the ultimate top displacement is evaluated based on the equal energy theorem (Figure 6).

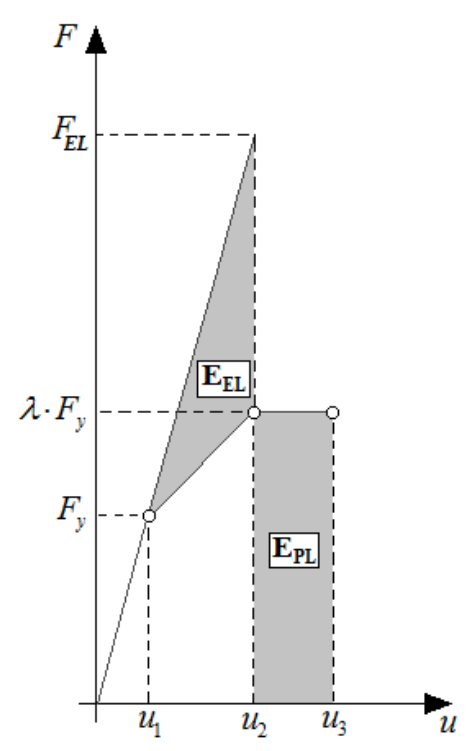

Figure 6. Equivalent elastic energy $\left(E_{E L}\right)$ and elasto-plastic energy $\left(E_{P L}\right)$ of the system.

According to the Figure 6, the energy balance between the equivalent elastic energy $\left(E_{E L}\right)$ and elasto-plastic energy $\left(E_{P L}\right)$ is reported in Equation (7).

$$
\left(u_{2}-u_{1}\right) \cdot \frac{\left(R_{\mu}-1\right)}{2}=\left(u_{3}-u_{2}\right)
$$

In the proposed approach, the two unknown displacement values are evaluated through an iterative procedure. The reduction factor value is fixed and then the displacement $u_{2}$ is assessed (Equation (8)). 


$$
u_{2}=\frac{R_{\mu, f i x e d} \cdot \lambda \cdot F_{y}}{k}
$$

where $k$ is the stiffness of the system. According to Equation (7), the ultimate top displacement $u_{3}$ is evaluated and then the reduction factor is calculated by using Equation (6). This iterative procedure continues until the corresponding calculated reduction factor converges for given initial approximation (Figure 7).

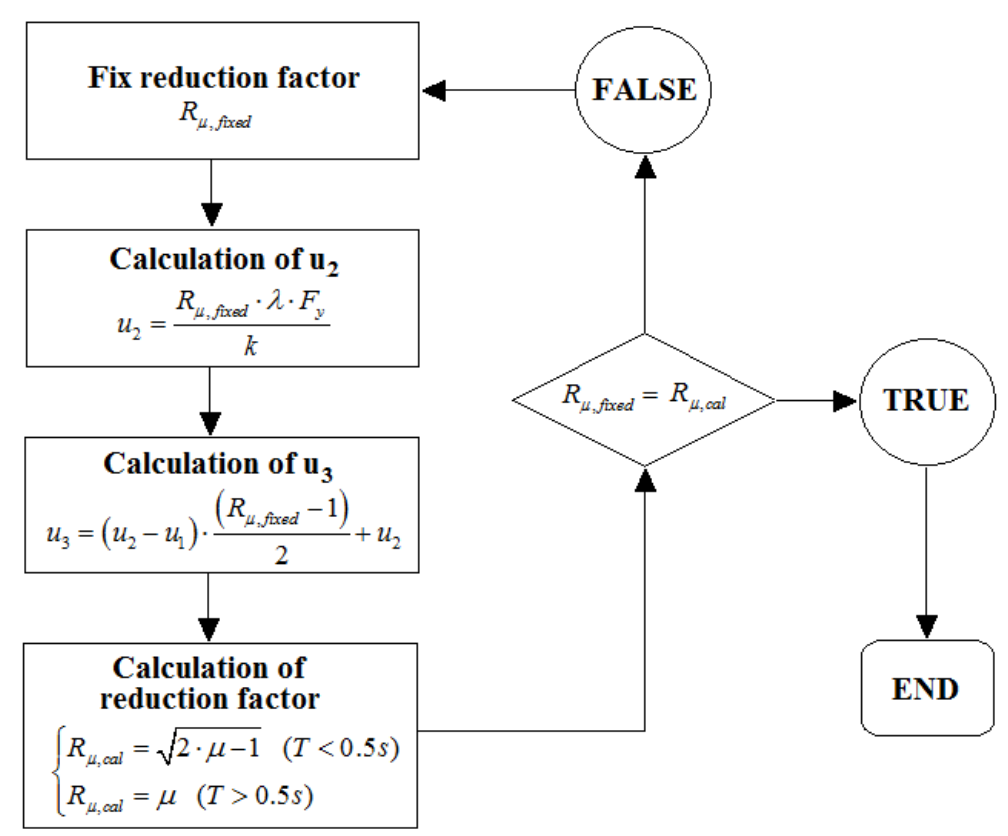

Figure 7. Iterative procedure for evaluating the reduction factor.

\section{ANALYSIS IMPLEMENTATION AND SIMULATION}

The proposed approach is capable of applying nonlinear time history analyses to a large number of buildings. The dynamic response of the structural system in a built environment takes into account a considerable amount of parameters. The building inventory, containing all the information (such as material, geometry and mechanical properties), has been developed and allocated on an external server. All this data are accessible by a MATLAB code organized in several functions that manage the seismic input definition, MCS for evaluation of the nonlinear parameters, and SAP2000 API actions. Due to the large number of variables and the time requested for processing, parallel algorithms running on multiple processors are developed with MATLAB.

\subsection{Software architecture}

The analysis flow is controlled through an interactive graphical user interface (GUI) that allows for selection of an earthquake scenario in the virtual city (magnitude and epicenter location). Furthermore, the acceleration time history can be selected and processed in both North-South (NS) and East-West (EW) directions. In order to take into account the deamplification of the seismic excitation with the epicenter distance, the shear wave velocity in the upper most $30 \mathrm{~m}\left(\mathrm{~V}_{\mathrm{S} 30}\right)$ for the city of Turin is included in the data. The $\mathrm{V}_{\mathrm{S} 30}$ map has been 
obtained via USGS website (USGS, 2013) at the link http://earthquake.usgs.gov/hazards/apps/vs30/. The Boore-Atkinson (Boore and Atkinson, 2008) attenuation law is used to estimate the attenuation of the time history's peaks. A Matlab function is provided for calculating distances between the selected epicenter and the center of the mass of each building. Moreover, the equivalent shear wave velocity is assessed according to the $\mathrm{V}_{\mathrm{S} 30}$ map, and considered in the attenuation model.

The main Matlab function controls the building's data flow, then the MCSs are carried out to evaluate the backbone curves for each building, considering the epistemic uncertainties in the input model parameters.

\subsection{SAP2000 API}

The SAP2000 Application Programming Interface (API) is a programming tool that offers efficient access to the analysis and design technology of the SAP2000 structural analysis software. A direct interaction with third-party applications is allowed during run-time analysis. The API software library provides access to a collection of objects and functions capable of remotely controlling the data exchange and setting data in SAP2000. Both pre- and postprocessing procedures are managed by a Matlab language code which mainly provides the two-way data exchange. This procedure is capable of significantly reducing the time needed for data exchange, especially for large data models.

Once the Matlab functions assess the nonlinear parameters (trilinear backbone curve) and the processed seismic input, they are transferred to SAP2000 through API tool. Due to the limited amount of detailed building information, the hysteresis is considered according to the Takeda model. Thus, the nonlinear time history analyses are performed in the SAP2000 environment and the derived output is remotely controlled by Matlab. Figure 8 shows in detail the software data flow used in the simulations.

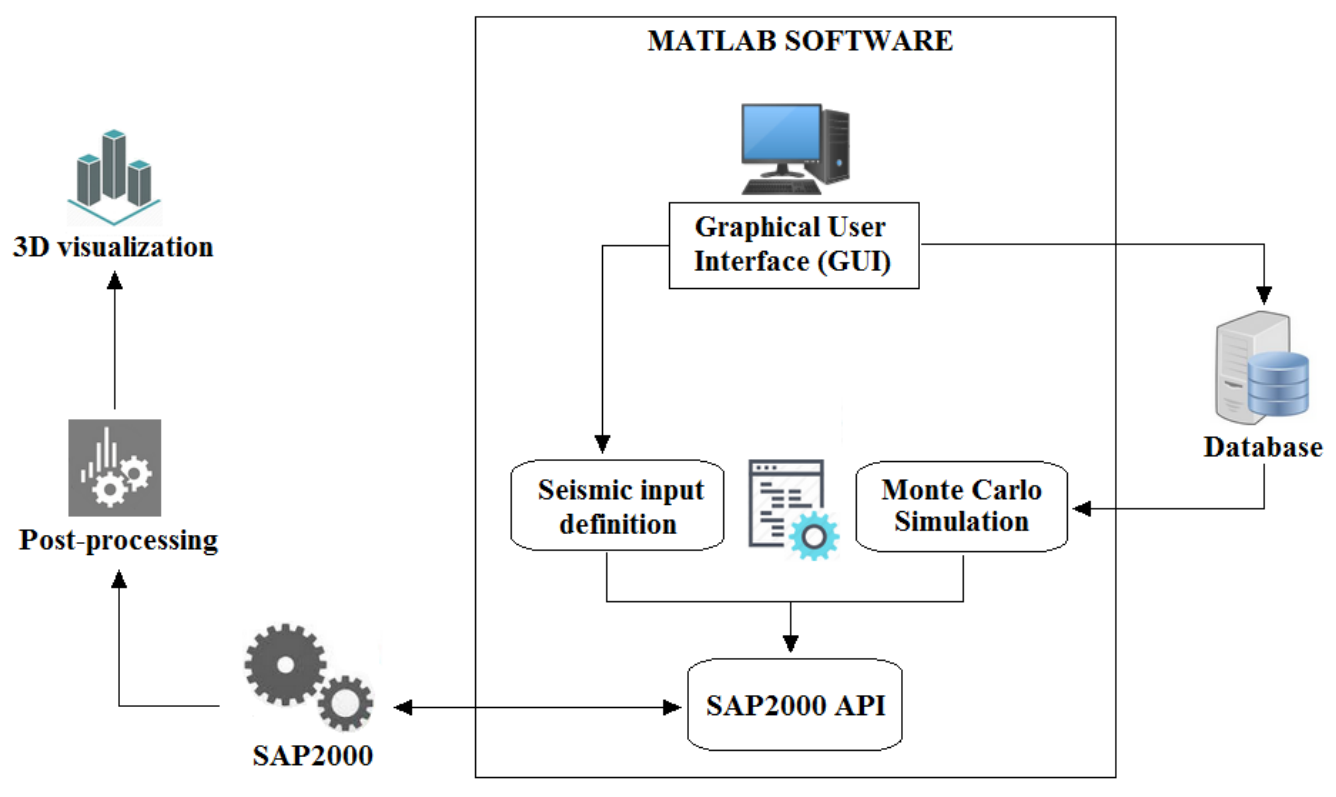

Figure 8. Software data flow. 
According to the maximum drift, the structural damage is assessed for each building and the associated level of damage is evaluated (slight, moderate, extensive, complete). A 3D visualization tool is also provided which shows the dynamic response of the building within the virtual city.

\section{CONCLUSIONS}

A new approach to implement dynamic time history analyses in a built environment of a virtual city is proposed. The virtual city has been designed based on the buildings stock for the city of Turin, Italy. All the characteristics of each residential building have been collected and organized in a complete database. The dynamic structural response has been simulated through a trilinear backbone curve through a nonlinear static approach for a MDOF system. The uncertainties on the building geometric and mechanical parameters have been taken into account through a MCS. Furthermore, an accurate selection and evaluation of the seismic input has been proposed. The dynamic response of the built environment have been carried out by SAP2000 software.

A Matlab based software has been developed to control the input data and the SAP2000 workflow through its Application Programming Interface. The post-processing is remotely controlled by Matlab, and the buildings' damage level is estimated. Finally, a 3D visualization tool is also provided which shows the dynamic response of the building within the virtual city. This procedure is capable to significantly reduce the time needed for data exchange especially for large data models. This methodology supports decision-maker to explore how their community responds to a disruptive event, quantify the performance of buildings following a hazard, and to plan the better resilience-building strategies to minimize the losses and recovery time.

\section{ACKNOWLEDGEMENTS}

The research leading to these results has received funding from the European Research Council under the Grant Agreement n ${ }^{\circ}$ ERC_IDEAL RESCUE_637842 of the project IDEAL RESCUE-Integrated Design and Control of Sustainable Communities during Emergencies.

\section{REFERENCES}

[1] MATLAB Version 2012b, Version 2012b Edition. Natick, MA: The MathWorks Inc., 2012.

[2] Computer and Infrastructure Inc. Sap2000, Version 17.3, Berkeley, CA.

[3] G.V. Fracastoro, G. Mutani, V. Verda, G. Vicentini, Analisi del fabbisogno di energia per gli edifici residenziali e della potenzialità del risparmio energetico e delle fonti rinnovabili in ambito urbano. Progetto Cities on Power, 2013.

[4] V. Corrado, I. Ballarini, S.P. Corgnanti, National scientific report on the TABULA activities in Italy, ISBN: 978-88-8202-039-2, 2012.

[5] X.Z. Lu, B. Han, M. Hori, C. Xiong, Z. Xu, A coarse-grained parallel approach for seismic damage simulations of urban areas based on refined models and GPU/CPU cooperative computing. Adv Eng Softw 70:90-103, 2014. 
[6] Z. Xu, X.Z. Lu, H. Guan, B. Han, A.Z. Ren, Seismic damage simulation in urban areas based on a high-fidelity structural model and a physics engine. Nat Hazards 71(3):1679-1693, 2014.

[7] D. Vamvatsikos, C.A. Cornell, Incremental dynamic analysis. Earthq Eng Struct Dyn 31 (3):491-514, 2002.

[8] W. Shi, X.Z. Lu, H. Guan, L.P. Ye, Development of seismic collapse capacity spectra and parametric study. Adv Struct Eng 17(9):1241-1256, 2014.

[9] EC2, Design of concrete structures-Part 1-1: General rules and rules for buildings. European Committee for Standardization, Bruxelles, BG, 2004.

[10] T.M. Takeda, Reinforced Concrete Response to Simulated Earthquakes. ASCE, Journal of the Structural Division, Vol. 96, No. ST12, , pp. 2557 - 2573, 1970.

[11] USGS, Seismic Hazard Analysis tools. U.S. Geological Survey. http://earthquake.usgs.gov/hazards/designmaps/grdmotion.php, 2013.

[12] D.M. Boore, G.M. Atkinson, Ground-motion prediction equations for the average 472 horizontal component of PGA, PGV, and 5\%-damped PSA at spectral periods between 0.01 s 473 and 10.0 s. Earthquake Spectra, 24(1), 99-138, 2008. 